\title{
Effects of Verticillium dahliae Infection of Cotton Plants (Gossypium hirsutum) on Potassium Levels in Leaf Petioles
}

\author{
J. E. DeVay, Department of Plant Pathology, University of California, Davis 95616; B. L. Weir, CE-DANR, Uni- \\ versity of California, Merced 95340; R. J. Wakeman, Department of Plant Pathology, University of California, \\ Davis; and J. J. Stapleton, Kearney Agricultural Center, University of California, Parlier 93648
}

\begin{abstract}
DeVay, J. E., Weir, B. L., Wakeman, R. J., and Stapleton, J. J. 1997. Effects of Verticillium dahliae infection of cotton plants (Gossypium hirsutum) on potassium levels in leaf petioles. Plant Dis. 81:1089-1092.

Two isolates of Verticillium dahliae, a black microsclerotial isolate and an isolate from potassium deficient cotton plants that forms white colonies on agar media, were examined for their effects on the potassium content of cotton plants. The potassium content of petioles from fully expanded leaves collected at random from branches 6 to 7 nodes below the terminal node were monitored during July and August in 1993 to 1995. Potassium contents of petioles from plants inoculated with $V$. dahliae did not differ significantly from plants injected with sterile water until the plants were nearing peak boll load. Both isolates caused a gradual development of potassium deficiency symptoms in leaves of inoculated plants and a decrease in petiole potassium, often accompanied by chlorosis and necrosis typical of Verticillium wilt. These results suggest that infection of cotton plants by $V$. dahliae causes an impairment in the uptake and translocation of potassium that is often associated with the development of potassium deficiency symptoms in leaves of plants with large boll loads.
\end{abstract}

Disease symptoms in cotton plants infected by Verticillium dahliae Kleb. are variable and often influenced by the strains of the pathogen. Among strains which infect cotton, two major groups have been recognized in pathogenicity tests, those which defoliate plants and those which do not (9). Strains which cause the most defoliation do so by inducing high amounts of ethylene in infected plants (13).

Leaf symptoms in cotton plants with Verticillium wilt are typified by interveinal chlorotic areas which later become necrotic. The chlorosis is caused by the occlusion of leaf veins in limited areas of leaves (7). The first appearance of these leaf symptoms, usually on lower leaves, is associated with a cessation of both plant growth and fruit development (4).

Less-recognized symptoms mimic potassium deficiency symptoms in infected plants; these symptoms do not stop growth, although they may cause reductions in growth and in lint yields (9). The potassium deficiency symptoms associated with infections of cotton plants by $V$. dahliae first appear in younger leaves and begin with bronzing at leaf margins. The leaves eventually develop a metallic sheen and

Corresponding author: J. E. DeVay

E-mail: jedevay@ucdavis.edu

Accepted for publication 22 June 1997.

Publication no. D-1997-0729-01R

(C) 1997 The American Phytopathological Society become thick and brittle, often resulting in extreme distortion of leaf tissues $(10,11,12)$. Frequently, the leaf symptoms of potassium deficiency and the chlorosis and necrosis associated with Verticillium wilt may both occur in single leaves.

Isolates of $V$. dahliae, including those that produce few microsclerotia and white colonies on agar media, have been isolated from cotton plants showing potassium deficiency symptoms. When inoculated into healthy plants, these isolates often induce similar potassium deficiency symptoms in cotton leaves (10). Among the isolates of $V$. dahliae recovered from fieldgrown cotton plants with severe leaf symptoms of potassium deficiency, approximately $23 \%$ produced white colonies on potato-dextrose agar medium (PDA), while other isolates produced gray $(25 \%)$ or black (52\%) microsclerotial colonies (10).

The possibility that potassium deficiency symptoms in cotton, which affects over 121,000 hectares of cotton in California, involves infection of the plants by $V$. dahliae is suggested by the following observations: (i) Since the early 1960s, the selection of new cultivars of Acala cotton for resistance to Verticillium wilt has resulted in a simultaneous selection for resistance to the potassium deficiency problem; and (ii) when highly susceptible cultivars (i.e., Acala SJ-2) are grown in fields where they develop potassium deficiency symptoms, foliar symptoms may be prevented by either soil solarization or fumigation with methyl bromide before planting and without additional fertiliza- tion with potassium $(11,12)$. Potassium translocation is impaired in cotton plants infected by $V$. dahliae $(5,6)$.

The present study sought to determine the effect $V$. dahliae on foliar symptoms and the potassium content of petioles of field-grown cotton plants with a comparison of black microsclerotial and white isolates.

\section{MATERIALS AND METHODS}

Location. This study was conducted at the San Juan Ranch and Bowles Ranch in Dos Palos, California, in cotton fields with little or no Verticillium wilt and where cotton plants had not shown potassium deficiency symptoms. The soil type at the San Juan Ranch was silty clay loam (20\% sand, $50 \%$ silt, and $30 \%$ clay), slightly alkaline (pH 7.5), and with 110 ppm exchangeable potassium at approximately 15 $\mathrm{cm}$ soil depth. The soil type at the Bowles Ranch was clay loam (35\% sand, $30 \%$ silt, and $35 \%$ clay), slightly alkaline ( $\mathrm{pH} 7.6)$, and with $120 \mathrm{ppm}$ exchangeable potassium at approximately $15 \mathrm{~cm}$ soil depth.

Cotton cultivars. The upland cotton (Gossypium hirsutum L.) cultivars used were susceptible to Verticillium wilt and often showed symptoms of severe potassium deficiency when grown in fields infested with $V$. dahliae. Cultivar Acala SJ-5 was planted in 1993 and Acala SJ-2 in 1994 and 1995.

Isolates of $\boldsymbol{V}$. dahliae and inocula for field tests. Prior to the experiments on potassium levels in cotton petioles, a field comparison of isolates of $V$. dahliae was made for their induction of wilt and potassium deficiency symptoms. Cultivar Acala SJ-2 was planted in 2 field sites and steminoculated using freshly prepared conidial suspensions in water $\left(10^{6}\right.$ conidia $\left.\mathrm{ml}^{-1}\right)$ from two-week-old cultures grown on PDA slants at 20 to $22^{\circ} \mathrm{C}$. A randomized complete block design was used with four replications. In each block, each treatment row was $3.1 \mathrm{~m}$ in length. Ten plants in the 10 to 11 node stage of growth in the midsection of each treatment row were used for inoculations with either isolate $1-\mathrm{K}-1$ or $2-\mathrm{K}-1$, both white isolates, and T-9-1, a black microsclerotial isolate. Stem injections with sterile water were used as a control. Colonies of white isolates on PDA were nonpigmented and produced scattered and very few black microsclerotia. The cultures were maintained on PDA at $10^{\circ} \mathrm{C}$. 

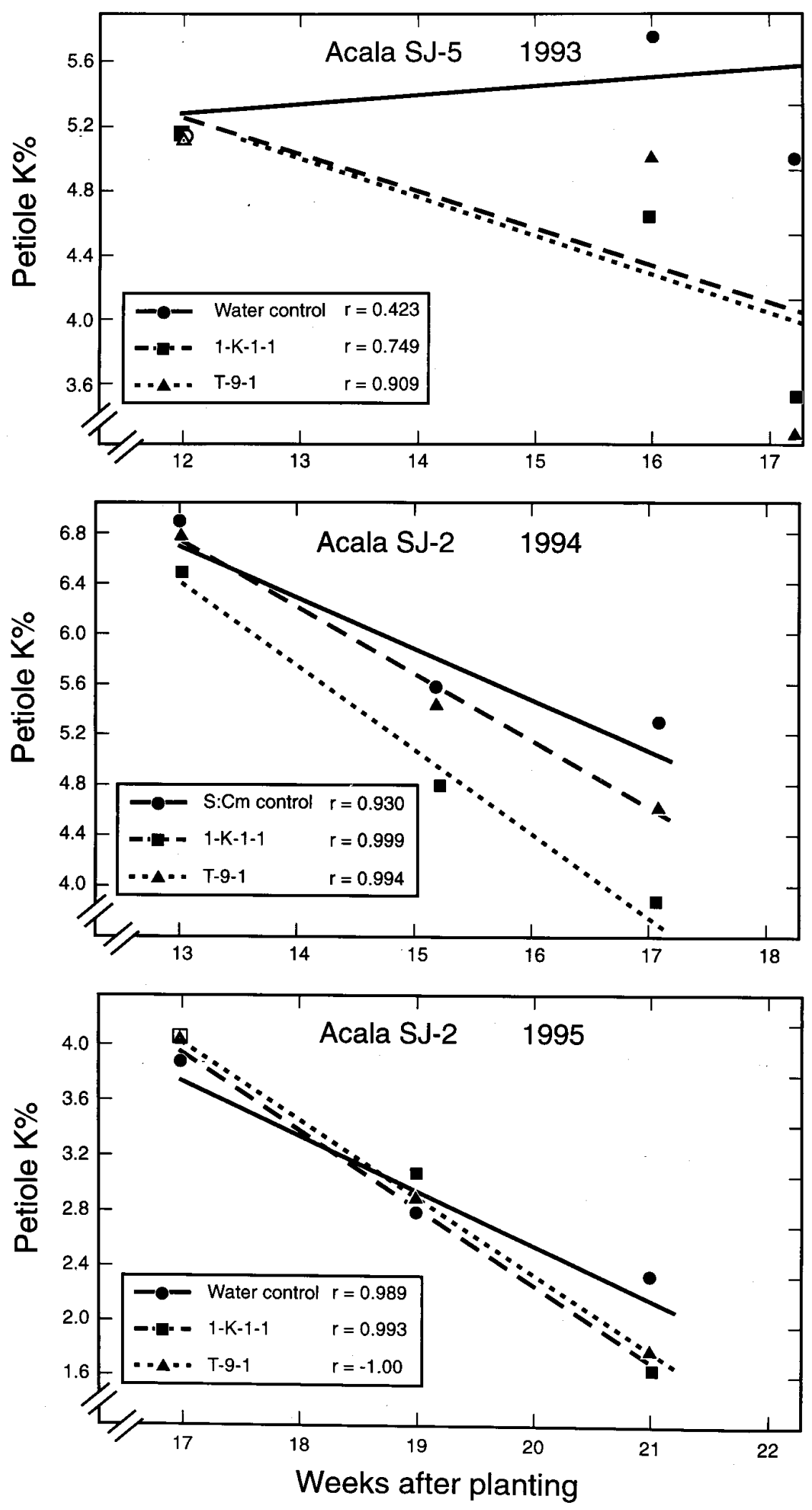

Fig. 1. Linear regressions of petiole potassium over time after planting showing the effect of Verticillium dahliae on the content of potassium in leaf petioles of cotton cultivars Acala SJ-2 and SJ-5. In 1993 and 1995, the plants were stem-inoculated with conidial suspensions of isolates 1-K-1-1 and T-9-1 at the San Juan Ranch. Plants injected with sterile water served as a control treatment. In 1994, cotton plants were grown in field sites at the Bowles Ranch, where soil was infested with a sand:cornmeal mixture colonized by isolates $1-\mathrm{K}-1-1$ or T-9-1. Sterile sand:cornmeal mixture was used as a control treatment. The first data point in each regression is the time of stem inoculation or soil infestation with $V$. dahliae. At the time of the second data point, the plants were approaching a full boll load, while the third data point is during the stage of full boll load and boll ripening. Data points in each regression are the means of four replications in each of two test sites each year.
The isolates used in the field tests on potassium levels in cotton petioles were 1K-1 and T-9-1. Two types of inocula were prepared. In 1993 and 1995, freshly prepared conidial suspensions in water as previously described were used, whereas in 1994, a sand:cornmeal mixture (95:5 $\mathrm{vol} / \mathrm{vol}$ ) was prepared which was placed in metal flats $(34 \mathrm{~cm}$ wide by $46 \mathrm{~cm}$ long by $9 \mathrm{~cm}$ deep), moistened, and steam-sterilized twice in autoclavable bags at $122^{\circ} \mathrm{C}$ for $4 \mathrm{~h}$. When cool, each flat was treated with $500 \mathrm{ml}$ of spore suspension and incubated at 20 to $22^{\circ} \mathrm{C}$ for 6 weeks. After 3 weeks' incubation, the mixture in each flat was turned and raked with a small garden claw. Before use in the field, the contents of the flats were combined and thoroughly mixed for each isolate.

Experimental design. In 1993 to 1995, duplicate experimental tests were made each year to determine the potassium levels in cotton petioles. Each site consisted of a randomized complete block design with three treatments and four replications. Treatment rows, spaced approximately 100 $\mathrm{cm}$ apart, were $3.3 \mathrm{~m}$ long and contained about 50 plants.

Inoculation with spore suspensions was done in 1993 and 1995 on individual plants at 20 nodes in height and 2 to 3 bolls/plant. Two microdroplets (about $10 \mu \mathrm{l}$ each) were placed on the lower stem of each plant and a sterile needle pushed through the droplets. The droplets were quickly sucked into the stem. The treatments consisted of inoculations with either a black microsclerotial isolate or a white isolate of $\mathrm{V}$. dahliae; sterile water injections were used as a control.

The same treatments were used in 1994 with duplicate tests except only soilborne inoculum was used. Inocula consisted of the sand:cornmeal mixture infested with the isolates of $V$. dahliae. Three weeks after planting, the sand:cornmeal mixture was buried about $15 \mathrm{~cm}$ deep on each side of the planting bed using $1000 \mathrm{~cm}^{3} / \mathrm{m}$ of row. For the control treatment, the noninoculated mixture was used.

The data collected consisted of potassium analyses of petiole samples picked three times prior to and during periods of peak boll loads in July and August. Each sample consisted of 30 expanded leaves chosen at random from branches 6 to 7 nodes below the terminal node from each treatment in each replication for each site.

Recovery of $\boldsymbol{V}$. dahliae from inoculated plants. Stem or petiole samples from 5 plants from each replication were collected and placed in plastic bags and kept cool in an ice chest. Subsamples approximately $1 \mathrm{~cm}$ long were rinsed under tap water, surface sterilized, and plated on PDA medium. Culture plates were incubated at 20 to $22^{\circ} \mathrm{C}$ for 7 to 14 days.

In field tests to compare the isolates of $V$. dahliae for induction of foliar symptoms, final ratings and the collection of 
plant samples were made in August when the plants were carrying a full boll load and within a week after the last irrigation. However, in the field tests on potassium contents of petioles, collection of plant samples for isolation of $V$. dahliae was delayed until after the final collection of petioles for potassium analysis and more than a month after the last irrigation.

Data analysis. For each year, analysis of covariance was used to calculate the linear regression of petiole potassium on weeks after planting for each treatment and to test the homogeneity of the slopes (8). Additionally, two contrasts were done: (i) water control versus treatments, and (ii) $1-\mathrm{K}-1-1$ versus T-9-1. Linear regressions of petiole potassium levels over time also were done using the MSTAT-C program.

Disease indices for potassium deficiency and wilt symptoms induced by the isolates of $V$. dahliae also were compared using the analysis of variance procedure in the MSTAT-C program.

\section{RESULTS}

Petiole analyses. Potassium levels in petiole samples for the different treatments were not significantly different in the first leaf collections. However, with increasing boll loads and corresponding increases in demand for potassium in the developing fruits, plants inoculated with $V$. dahliae began to show a greater decrease in petiole potassium compared with control plants (Fig. 1). The slopes are shown in Table 1. The probabilities for the test of homogeneity of slopes were not significant $(P>$ $0.05)$, but the contrast for control versus treatments was significant $(P<0.05)$ for 1993 and 1994 (Table 1). There were no significant differences $(P>0.05)$ for 1995 . The treatments with $V$. dahliae, in general, showed a more rapid decline in petiole potassium over time than did the control treatments.

Induction of foliar symptoms by $V$. dahliae. In field tests separate from those on potassium content in leaf petioles, the induction of foliar symptoms by isolates of $V$. dahliae was rated using a disease index for potassium deficiency symptoms and one for wilt symptoms (Table 2). The white isolates, $1-\mathrm{K}-1-1$ and $2-\mathrm{K}-1$, and the black microsclerotial isolate, T-9-1, all caused severe foliar symptoms of potassium deficiency and also the chlorosis and necrosis in leaves associated with Verticillium wilt, in contrast to the symptomless control plants. Some leaves of inoculated plants had both potassium deficiency and wilt symptoms, whereas other leaves had one or the other kind of symptoms. Limited defoliation of inoculated plants was apparent in the field tests in contrast to greenhouse tests (data not shown), where T-9-1 and the white isolates caused severe defoliation in test plants.

The pattern of leaf symptoms induced in inoculated plants used for analysis of po- tassium contents of petioles was similar to that in Table 2, but because of destructive sampling of leaves, quantitative data were not recorded. The occurrence of typical symptoms of Verticillium wilt, including stunting of plants and patches of leaf chlorosis in lower leaves, were apparent before significant changes in petiole content of potassium were found. However, with increasing boll loads and a strong drain of leaf potassium into developing fruits, potassium deficiency symptoms began to develop. Control plants injected with sterile water had no symptoms of either potassium deficiency or wilt.

In 1994, infestation of soil with $V$. dahliae caused significant decreases in potassium content of petioles and induction of both Verticillium wilt and potassium deficiency symptoms in leaves similar to those caused by stem inoculations in 1993 when compared to control plants. Control plants treated with uninoculated sand:cornmeal mixture showed no symptoms of Verticillium wilt or symptoms of potassium deficiency.

Recovery of $V$. dahliae from test plants. Among the isolates of $V$. dahliae used, the black microsclerotial isolate, T-91 , was recovered from all inoculated plants sampled. However, isolate 1-K-1-1 was difficult to recover from plant samples obtained after the last leaf collections were made and more than a month after the last soil irrigation; successful isolations were made from approximately $25 \%$ of the in-

Table 1. Treatment comparison of slopes from linear regression of petiole potassium on weeks after planting for each year

\begin{tabular}{lrrr}
\hline Treatment & $\mathbf{1 9 9 3}$ & $\mathbf{1 9 9 4}$ & $\mathbf{1 9 9 5}$ \\
\hline Water control & 0.050 & -0.368 & -0.400 \\
Isolate 1-K-1-1 & -0.240 & -0.515 & -0.561 \\
$\quad$ Isolate T-9-1 & -0.227 & -0.622 & -0.575 \\
Contrasts & & & \\
$\quad$ Control vs. isolates & $* \mathrm{y}$ & $*$ & $\mathrm{NS}^{\mathrm{z}}$ \\
1-K-1-1 vs. T-9-1 & $\mathrm{NS}$ & $\mathrm{NS}$ & $\mathrm{NS}$ \\
\hline
\end{tabular}

$\mathrm{y} *=P<0.05$

${ }^{\mathrm{z}} \mathrm{NS}=$ not significant.

Table 2. Development of potassium deficiency and wilt symptoms in leaves of cotton cultivar, Acala SJ-2, stem-inoculated with Verticillium dahliae

\begin{tabular}{lcc}
\hline & \multicolumn{2}{c}{ Indices of foliar symptoms } \\
\cline { 2 - 3 } Treatments & Potassium deficiency $^{\mathbf{x}}$ & ${\text { Verticillium } \text { wilt }^{\mathbf{y}}}$ \\
\hline Field site 1 & $1.5 \mathrm{a}^{\mathrm{z}}$ & $1.1 \mathrm{a}^{\mathrm{z}}$ \\
$\quad$ Sterile water injection & $2.8 \mathrm{~b}$ & $1.9 \mathrm{~b}$ \\
$\quad$ Isolate 1-K-1-1 (white colony) & $2.9 \mathrm{~b}$ & $2.0 \mathrm{~b}$ \\
$\quad$ Isolate T-9-1 (black microsclerotial colony) & & \\
Field site 2 & $1.3 \mathrm{a}$ & $1.0 \mathrm{a}$ \\
$\quad$ Sterile water injection & $2.9 \mathrm{~b}$ & $2.0 \mathrm{~b}$ \\
$\quad$ Isolate 2-K-1 (white colony) & $3.0 \mathrm{~b}$ & $3.1 \mathrm{c}$ \\
$\quad$ Isolate T-9-1 (black microsclerotial colony) &
\end{tabular}

${ }^{\mathrm{x}}$ Index for potassium deficiency was on a scale of 1 to $3: 1=$ healthy; $2=$ leaves bronzed with metallic sheen; and $3=$ leaves as in 2 , but thickened and brittle.

${ }^{\mathrm{y}}$ Index for Verticillium wilt was on a scale of 1 to $4: 1=$ healthy; $2=$ often stunted plants with chlorotic areas in one or two leaves; $3=$ extensive chlorosis and necrosis in two or more leaves; and 4 as in 3 but with defoliation.

${ }^{z}$ Values are means of four replications with 10 duplicates per replication. Means in columns followed by the same letter are not significantly different $(P>0.05)$. 
$V$. dahliae, in general, showed a more rapid decline in petiole potassium than did the water control, with the contrast for the water control versus the fungal treatments being significant for 1993 and 1994.

Quantitative data on the development of disease or potassium deficiency symptoms in test plants used for leaf samples were not taken because of the extensive leaf sampling during the season; however, general observations on the occurrence of both Verticillium wilt symptoms and symptoms of potassium deficiency were made and were similar to those previously found (Table 2).

Because white isolates of $V$. dahliae have only been recovered from cotton plants with potassium deficiency symptoms, and because they can induce the potassium deficiency symptoms in greenhouse and field plants inoculated with conidial suspensions, their possible role in the problem is suggested (10). These studies also showed that other strains of $V$. dahliae would induce the potassium deficiency symptoms along with the typical chlorotic patchiness in leaves associated with Verticillium wilt.

The low frequency in recovery of white isolate 1-K-1-1 from plant samples obtained a month or more after the last soil irrigation when plant moisture stress is increasing was not surprising; low recovery frequencies were experienced in previous field experiments except when isolations were made soon after soil irrigations. In contrast to white isolates, black microsclerotial isolates such as T-9-1 are easily recovered from infected plant tissues, and it appears that moisture stress in foliage is less important in their recovery.

Potassium translocation is impaired in cotton plants infected by $V$. dahliae (5), and cultures of this pathogen produce metabolites which have an unusually high affinity for potassium ions (3). The current study shows that $V$. dahliae infection can reduce the potassium content of cotton foliage under field conditions.

The possible role of $V$. dahliae in the potassium deficiency problem in California was overlooked for over 30 years. Experimental evidence in the current work points to involvement of this pathogen in the development of potassium deficiency symptoms.

\section{ACKNOWLEDGMENTS}

We thank E. Sue Littlefield in the Division of Agriculture and Natural Resources Analytical Laboratory, University of California, Davis, for assistance with the petiole analyses; and Carol Adams, Riverside, California, for assistance with statistical analyses.

\section{LITERATURE CITED}

1. Ashworth, L. J., George, A. G., and McCutcheon, O. D. 1982. Disease-induced potassium deficiency and Verticillium wilt. Calif. Agric. 36:18-20.

2. Brown, A. L., Quick, J., and DeBoer, G. J. 1973. Diagnosing potassium deficiency by soil analysis. Calif. Agric. 27:13-14.

3. Gour, H. N., and Dube, H. C. 1985. Effects of ouabain and phytotoxic metabolites from Verticillium dahliae on the cell membranes of cotton plants. Physiol. Plant Pathol. 27:109-118.

4. Gutierrez, A. P., DeVay, J. E., Pullman, G. S., and Friebertshauser, G. E. 1983. A model of Verticillium wilt in relation to cotton growth and development. Phytopathology 73:89-95.

5. Hafez, A. A., Stout, P. R., and DeVay, J. E. 1975. Potassium uptake by cotton in relation to Verticillium wilt. Agron. J. 67:359-361.

6. Mikkelsen, D. S., Weir, B. L., Abshahi, A., and Hafez, A. A. 1988. Disease-induced potassium deficiency in cotton. Pages 514-515 in: Proc. 1988 Beltwide Cotton Research Conferences. J. M. Brown, ed. National Cotton Council of America, Memphis, TN.

7. Misaghi, I. J., DeVay, J. E., and Duniway, J. M. 1978. Relationship between occlusion of xylem elements and disease symptoms in leaves of cotton plants infected with Verticillium dahliae. Can. J. Bot. 56:339-342.

8. Steel, R. G. D., and Torrie, J. H. 1980. Principles and Procedures of Statistics, a Biometrical Approach. Second Ed. McGraw-Hill, New York.

9. Tzeng, D. D., and DeVay, J. E. 1985. Physiological responses of Gossypium hirsutum L. to infection by defoliating and nondefoliating pathotypes of $V$. dahliae Kleb. Physiol. Plant Pathol. 26:57-72.

10. Wakeman, R. J., DeVay, J. E., Paplomatas, E. J., and Weir, B. L. 1991. The association of white strains of Verticillium dahliae with the potassium deficiency syndrome in cotton. (Abstr.) Page 190 in: Proc. 1991 Beltwide Cotton Research Conferences. D. J. Herber and D. A. Richter, eds. National Cotton Council of America, Memphis, TN.

11. Weir, B. L., DeVay, J. E., and Wakeman, R. J. 1992. In fumigating Verticillium-infested soils, potassium deficiencies in cotton go down, yields go up. Calif. Agric. 46:17-18.

12. Weir, B. L., Garber, R. H., Stapleton, J. J., Felix-Gastelum, R., Wakeman, R. J., and DeVay, J. E. 1989. Control of potassium deficiency syndrome in cotton by soil solarization. Calif. Agric. 43:26-28.

13. Wiese, M. V., and DeVay, J. E. 1970. Growth regulator changes in cotton associated with defoliation caused by Verticillium albo-atrum Plant Physiol. 45:304-309. 